\title{
EDUKASI DAN PENDAMPINGAN DIET LANSIA DENGAN HIPERTENSI
}

\author{
Bambang Soewito'), Marta Pastari'1) \\ 1)Jurusan Keperawatan, Politeknik Kesehatan Palembang, Palembang, Sumatera Selatan Indonesia \\ Corresponding author :Marta Pastari \\ E-mail :marta@poltekkespalembang.ac.id
}

Diterima 28 November 2021, Direvisi 30 November 2021, Disetujui 30 November 2021

\begin{abstract}
ABSTRAK
Hipertensi adalah penyakit kronis yang umum di seluruh dunia dan faktor risiko utama penyakit kardiovaskular. Desa Sumber Harta Kabupaten Musi Rawas merupakan salah satu desa yang terletak di daerah dataran rendah padat penduduk yang rata-rata pekerjaannya sebagai petani. Data Puskesmas Sumber Harta menyebutkan bahwa angka kejadian hipertensi pada lansia sangat tinggi bahkan kunjungan terbanyak adalah penderita hipertensi mencapai $70 \%$. Para lansia ini juga kurang memahami dampak jangka Panjang hipertensi seperti stroke. Tujuan dalam pengabdian ini adalah untuk meningkatkan pengetahuan lansia dan keluarga dalam mencegah komplikasi hipertensi. Mitra dalam pengabdian ini adalah Puskesmas dan Desa Sumber Harta (RT 09 dan 10). Peserta dalam kegiatan ini adalah lansia penderita hipertensi dan keluarga sebanyak 18 orang. Metode dalam kegiatan ini yaitu penyuluhan dan pendampingan pengelolaan diet hipertensi bersama keluarga. Keberhasilan tampak dari semangat dan antusiasnya lansia beserta keluarga. Lansia maupun keluarganya juga berperan aktif dalam menjawab evaluasi tentang materi yang telah disampaikan dan dapat mendemonstrasikan kembali pengolahan bahan makananan untuk diet hipertensi. Pelaksanaan kegiatan pengabdian terlaksana dengan lancar, pengetahuan lansia dalam memahami diet hipertensi bertambah serta berkomitmen dalam melaksanakan semua anjuran dari tim pengabdian untuk mencegah komplikasi hipertensi.
\end{abstract}

Kata kunci: hipertensi; diet; lansia.

\section{ABSTRACT}

Hypertension is a common chronic disease worldwide and a major risk factor for cardiovascular disease. Sumber Harta Village, Musi Rawas Regency is one of the villages located in a densely populated lowland area whose average occupation is as a farmer. Data from the Sumber Harta Health Center stated that the incidence of hypertension in the elderly was very high, even the most visits were people with hypertension reaching $70 \%$. These elderly people also do not understand the long-term impact of hypertension such as stroke. The purpose of the service is to increase the knowledge of the elderly and their families in preventing complications of hypertension. Partners in this service are Puskesmas and Sumber Harta Village (RT 09 and 10). Participants in this activity are elderly people with hypertension and their families as many as 18 people. The method in this activity is counseling and assistance in managing hypertension diet with the family. The success of this event can be seen from the enthusiasm and enthusiasm of the elderly and their families. The elderly and their families also play an active role in answering the evaluation of the material that has been submitted and can demonstrate again the processing of food ingredients for the hypertension diet. The implementation of service activities was carried out smoothly, the knowledge of the elderly and their families in understanding the hypertension diet increased and they were committed to carrying out all the recommendations from the service team to prevent complications of hypertension

Keywords: hypertension; diet; elderly people

\section{PENDAHULUAN}

Hipertensi merupakan faktor risiko penting untuk penyakit neurologis. Hipertensi kronis merupakan faktor risiko utama untuk semua subtipe stroke, termasuk stroke iskemik, perdarahan intraserebral dan perdarahan subarachnoid. Hipertensi telah menjadi faktor risiko utama untuk penyakit kronis dan kematian. WHO merekomendasikan pentingnya pelayanan kesehatan primer dalam memerangi hipertensi dan tenaga kesehatan, terutama perawat, harus berperan dalam menciptakan kesadaran diantara anggota masyarakat dan mereka harus berperan aktif dalam menyelenggarakan pendidikan Kesehatan tentang faktor risiko (Frits, 2018). Kejadian hipertensi akan bertambah dengan bertambahnya umur seseorang. Pada usia 25 sampai 44 tahun kejadian hipertensi mencapai $29 \%$, pada usia 45 sampai 64 tahun mencapai 
$51 \%$, dan pada usia lebih 65 tahun mencapai $65 \%$. (Sunaryo, dkk, 2016). Meningkatnya kejadian penyakit darah tinggi mengakibatkan jumlah kematian serta terjadinya risiko komplikasi akan semakin bertambah setiap tahunnya. Penyebab keadaan ini karena hipertensi angka kejadiannya masih sangat tinggi di wilayah yang berpenghasilan rendah dan terjadi pada usia lanjut, maka diperlukan solusi terbaik untuk mengatasi hipertensi. Solusi yang diharapkan dapat menurunkan angka kejadian hipertensi, menurunkan risiko terjadinya komplikasi dan mengurangi risiko terhadap penyakit bagian kardiovaskuler (Awaludin, dkk, 2020).

Di Asia Tenggara hampir 1,5 juta jiwa meninggal disebabkan oleh penyakit hipertensi tiap tahun, kondisi ini menjadikan darah tinggi menjadi faktor tertinggi penyebab kematian. Riset Kesehatan Dasar 2018 menyebutkan kejadian hipertensi di Sumatera Selatansebesar $7,34 \%$ dari total penduduk yang juga termasuk lansia. Sebagian besar lansia di Kabupaten Musi Rawas berada pada Klasifikasi Hipertensi Derajat I (tekanan darah $140-159 \mathrm{mmHg}$ ) dengan rata-rata usia 56-60 tahun (Tim Riskesdas, 2019).

Laban(Fernalia\&Jumaiyah,

menyatakan bahwa mencegah dan mengatasi masalah hipertensi di Indonesia harus dimulai dengan menambah tingkat kesadaran masyarakat dalam membuat perubahan kebiasaan hidup yang lebih sehat. Demi mewujudkan hal tersebut, maka perlu dilakukan kegiatan pengabdian masyarakat dalam bentuk Skrinning dan Penyuluhan tentang Hipertensi.

Penderita hipertensi mayoritas mempunyai keluhan bergantung pada anda dan gejala yang dirasakan pada saat itu tanpa peduli terhadap penanganan yang lebih intensif dan tepat. Kondisi ini dapat diakibatkan karena kurangnya pengetahuan masyarakat pada penyakit hipertensi serta penanganan yang baik dan tepat secara rutin (Sunaryo, dkk, 2016). Rekomendasi dalam mengatasi hipertensi sebisa mungkin dilaksanakan dengan maksimal oleh penderita hipertensi dan tim kesehatan melalui tindakan farmakologis dan non farmakologis untuk menurunkan tekanan darah. Rekomendasi untuk self management hipertensi menurut The European Society of Hypertension meliputi modifikasi gaya hidup dan terapi pengobatan. Penatalaksanaan non farmakologis dalam mengurangi kejadian hipertensi dapat dilaksanakan dengan memodifikasi gaya hidup. Basit, dkk (2019),berpendapat jikapenderita hipertensi yang memodifikasi gaya hidup dalam mengontrol tekanan darahnya terdapat sebanyak $30 \%$ dari seluruh penderita hipertensi. Seseorang yang menderita penyakit kardiovaskuler diharapkan untuk melakukan perawatan terhadap dirinya sendiri sebagai salah satu penanganan penyakit untuk meningkatkan kualitas hidup.

Modifikasi gaya hidup juga mengharuskan pasien untuk dapat membaca label makanan dan memilih makanan sehat. Rekomendasi manajemen hipertensi menurut Basit, dkk (2019) yaitu modifikasi perilaku hidup sehat, kurangi berat badan, kurangi konsumsi alkohol, manajemen diet, pembatasan sodium, diet kalsium maupun magnesium dan menghindari stress. Manajemen diri hipertensi diharapkan untuk meningkatkan pengetahuan lansia pada penyakit hipertensi, memperbaiki sikap dan kepatuhan pengobatan penyakitnya. Semuanya bisa diterapkan dengan cara pemberian edukasi pada penderita hipertensi yang bertujuan mengurangi tekanan darah dan faktor-faktor risiko terjadinya hipertensi. Agar lansia penderita hipertensi peduli kesehatan tentang hipertensi, tenaga kesehatan perlu membekali mereka dengan penyuluhan kesehatan hipertensi dan menjelaskan tentang hipertensi, penatalaksanaan dan prognosisnya (Suprayitno, E, \& Wahid, A, 2019). Setelah itu, pasien memiliki tanggung jawab untuk memahami dan mengikuti rejimen penatalaksanaan hipertensi sesuai dengan resep mereka untuk manajemen sukses diet dan pengendalian hipertensi (Suprayitno, 2020). Tujuan Kegiatan pengabdian ini adalah untuk meningkatkan pengetahuan Lansia tentang Hipertensi dan memberikan motivasi menjaga kesehatan secara mandiri serta memberikanimplementasi menurunkan tekanan darah pada lansia dengan menggunakan Air Kelapa Muda.

\section{METODE}

Pengabdian masyarakat ini dilaksanakan pada hari Kamis, 11 Maret 2021, di SDN 1 Desa Sumber Harta Kabupaten Musi Rawas. Mitra dalam kegiatan ini adalah Masyarakat RT 09 dan 10 Desa Sumber Harta Kabupaten Musi Rawas. Peserta pengabdian yaitu 18 orang lansia penderita hipertensi. Metode yang digunakan dalam pengabdian masyarakat ini adalah melakukan home visit dan kontrak waktu dengan keluarga lansia, pemeriksaan tanda vital, penyuluhan dan penyerahan media penyuluhan sekaligus demonstrasi pentingnya air kelapa muda dalam menurunkan hipertensi. Penyuluhan dan ceramah dilakukan melalui penyampaian materi terkait pengertian, faktor penyebab, tanda gejala dan pencegahan komplikasi hipertensi. Narasumber berasal dari dosen jurusan keperawatan Poltekkes Kemenkes 
Palembang. Kegiatan yang terakhir adalah diskusi dan tanya jawab tentang penyakit dan diet hipertensi dilakukan setelah penyuluhan, kemudian dilakukan demonstrasi contoh diet hipertensi bagi lansia.

\section{HASIL DAN PEMBAHASAN}

Kegiatan pengabdian pendampingan lansia dalam mencegah komplikasi hipertensi dan diet hipertensi dilaksanakan di SDN 1 Desa Sumber Harta Kabupaten Musi Rawas. Pelaksanaan pendampingan pencegahan komplikasi hipertensi pada lansia terlaksana tanpa hambatan dan lancar. Kegiatan ini dilaksanakan dengan tahapan :

1. Pemeriksaan tanda-tanda vital

Tahapan yang pertama adalah pemeriksaan tekanan darah yang dibantu oleh mahasiswa program studi keperawatan. Kegiatan terlihat pada gambar 1 di bawah ini;

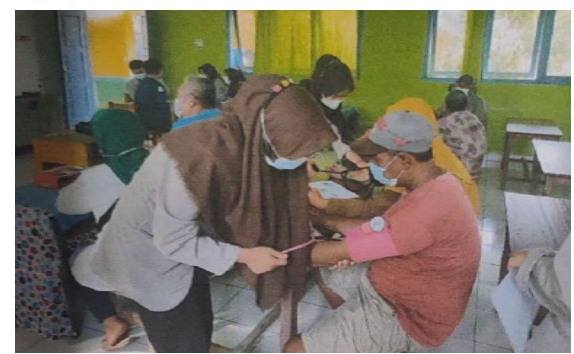

Gambar 1. Pemeriksaan Tekanan Darah

2. Proses Penyampaian materi dengan metode ceramah

Tahapan kedua adalah menjelaskan materi dengan melaksanakan metode ceramah. Pada tahapan ini lansia diberikan penjelasan materi tentang hipertensi meliputi: pengertian, faktor penyebab, tanda gejala, komplikasi dan cara pencegahannya serta diet hipertensi bagi lansia.Kegiatan diskusi tanya jawab tentang materi yang telah disampaikan. Kegiatan terlihat pada Gambar 2 di bawah ini;

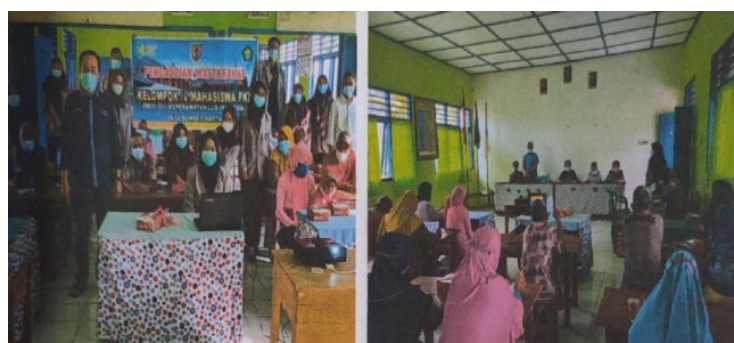

Gambar 2. Penyampaian Materi

3. Pelaksanaan kegiatan diskusi

Pada tahapan ini menerapkan metode diskusi (tanya jawab). Lansia berdiskusi tentang materi pendampingan yang telah dijelaskan. Bagi lansia yang kurang paham maka lansia diperkenankan untuk bertanya.
Selanjutnya diakhir kegiatan lansia diberikan beberapa evaluasi terkait materi yang sudah dibahas. Kegiatan terlihat pada Gambar 3 di bawah ini;

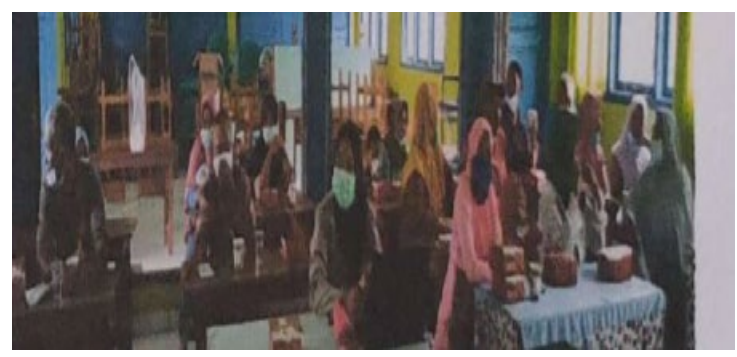

Gambar 3. Diskusi

Keberhasilan pendampingan pencegahan komplikasi hipertensi lansia di rumah dan kepatuhan diet bertujuan meningkatkan motivasi lansia dapat dilihat dari antusiasme dan semangat lansia yang ikut dalam pendampingan serta selalu bertanya terkait penyakit hipertensi. Para lansia rutin dan tepat waktu pada saat acara pendampingan. Selain itu lansia juga berperan aktif dalam melaksanakan proses diskusi, mereka tanpa merasa segan mengajukan pertanyaan jika terdapat materi pendampinganyang tidak jelas dan sulit dimengerti. Mereka juga aktif menjawab pertanyaan seputar materi yang telah disampaikan oleh pengabdi. Kegiatan pendampingan tentang pencegahan komplikasi hipertensi ini membantu lansia dalam mengatasi ketiadaktahuannya tentang pencegahan komplikasi hipertensi. Sebagian besar lansia sudah bersikap positif terhadap pencegahan komplikasi hipertensi dan diet hipertensi.

\section{SIMPULAN DAN SARAN}

Kesimpulan dalam Kegiatan pendampingan pencegahan komplikasi hipertensi dan diet hipertensi di SDN 1 Desa Sumber Harta Kabupaten Musi Rawas adalah dapat meningkatkan pengetahuan lansia tentang hipertensi dan pencegahan komplikasinya, menumbuhkan motivasi lansia untuk mencegah komplikasi penyakit dan melaksanakan diet serta gayahidup yang baik dalam kehidupan sehai-hari. Keberhasilan pendampingan lansia untuk menumbuhkan motivasi dalam pencegahan komplikasi penyakit hipertensi dan diet hipertensi adalah dengan antusias dan semangat dalam mengikuti kegiatan pengabdian. Selain itu lansia juga aktif dalam melakukan tanya jawab dengan pengabdi.

\section{UCAPAN TERIMAKASIH}

Tim penulis mengucapkan terima kasih kepada Direktur Poltekkes Kemenkes Palembang, 
Kepala Pusat Penelitian dan Pengabdian Kepada Masyarakat (P2M) Poltekkes Kemenkes Palembang, Ketua Jurusan Keperawatan Poltekkes Kemenkes Palembang, Pimpinan Puskesmas Sumber Harta, Kepala Desa Sumber Harta, Masyarat RT 09 dan 10 Desa Sumber Harta Kabupaten Musi Rawas Provinsi Sumatera Selatan

\section{DAFTAR RUJUKAN}

Laban, dkk. (2016).Seluk Beluk Hipertensi: Peningkatan Kompetensi Klinis Untuk Pelayanan Kefarmasian. Yogyakarta: Sanata Dharma University Press

Sunaryo, dkk. (2016). Asuhan Keperawatan Gerontik. Yogyakarta: CV Andi Offse

Frits. (2018). Buku Referensi Hipertensi. Jakarta: Fakultas Kedokteran Universitas Kristen Indonesia

Basit, dkk. (2019). Program Pelangi (Pengontrol Diet Pada Lansia Dengan Hipertensi) di Sei Lulut Banjarmasin. Jurnal Suaka Insan Mengabdi (JSIM). 1(1). 33-41. https://doi.org/10.51143/jsim.v1i1.140

Tim Riskesdas. (2019). Laporan Provinsi Sumatera Selatan Riskesdas 2018. Jakarta:Lembaga Penerbit Badan Penelitian dan Pengembangan Kesehatan

Fernalia, F., Busjra, B., \& Jumaiyah, W. (2019). Efektivitas Metode Edukasi Audiovisual terhadap Self Management pada Pasien Hipertensi. Jurnal Keperawatan Silampari, $\quad 3(1), \quad$ 221-233. https://doi.org/10.31539/jks.v3i1.770

Suprayitno, E. (2019). Gambaran Status Tekanan Darah Penderita Hipertensi di Desa Karanganyar Kecamatan Kalianget Kabupaten Sumenep. Journal Of Health Science (Jurnal IImu Kesehatan), 4(2), 20-24. https://doi.org/10.24929/jik.v4i2.799

Suprayitno, E, \& Wahid, A. (2019). Pendampingan Tentang Penyakit Hipertensi Dan Perawatan Keluarga Dengan Hipertensi. Seminar Nasional Hasil Pengabdian, 104-106. http://proceeding.uim.ac.id/index.php/se nias/article/view/299

Awaludin, dkk. (2020). Pengabdian Masyarakat Berbasis Hasil Riset: Kelas Tensi (Kelompok Lansia Sadar Hipertensi) Sebagai Upaya Preventif Penyakit Jantung Koroner. Jurnal Pengabdian Kepada Masyarakat (ABDIMAS). 24(2). 142-147.

https://journal.unnes.ac.id/nju/index.php/ abdimas/article/view/16741/11323
Suprayitno, E, Purnomo, J. D. T., Sutikno, S., \& Indriyani, R. (2020). Health education in principle of community affected teenagaer's smooking attitude and habitual in the coastal area of madura island indonesia. International Journal of Psychosocial Rehabilitation, 24(10), 1492-

1502.https://doi.org/10.37200/IJPR/V24I 10/PR300173

Suciati dan Rustiana. (2021). Pemeriksaan Tekanan Darah Dan Konseling Tentang Hipertensi dan Komplikasinya Pada Lansia Di Desa Kromasan Kabupaten Tulungagung. Jurnal Penelitian dan Pengabdian Kepada Masyarakat Universitas Tulung Agung (JANITA). 1(1). 31-36. https://doi.org/10.36563/pengabdian.v1i1 .283 